\title{
Analysis of shape correctness of surfaces of diamond burnished components
}

\author{
Gyula Varga $^{1 *}$ and Viktoria Ferencsik ${ }^{1}$ \\ ${ }^{1}$ University of Miskolc, Institute of Manufacturing Science, 3515 Miskolc, Egyetemváros, Hungary
}

\begin{abstract}
In these days, diamond burnishing is frequently used for final finishing manufacturing operations of components. Diamond burnishing belongs to cold plastic manufacturing procedures. When using this technique, the following advantages can be obtained: micro-hardness of near surface layer is increasing; surface roughness is improving and the shape correctness is also improving. This paper deals with how the different technological parameters of burnishing, such as the feed rate, the burnishing speed and the burnishing force effect on the cylindricity of the burnished workpiece. The experiment was done on some specimen having outer cylindrical surfaces. The experiments were executed by the Taguchi type Full Factorial Experiment Design method with which empirical formulas can be efficiently created. The measurements of the cylindricity of specimens were done with a circular and position error measuring. From the measured data, special improvement ratios were calculated in order to define the appropriate range of technological parameters which results high improvements. Further aim was to compare the measured values of different cylindricity parameters.
\end{abstract}

\section{Introduction}

The development of production engineering and manufacturing is an important part of realization of the tasks determined in the Industry 4.0 [1] in environmentally way $[2,3]$. In the last decade, the researches dealing with the shape correctness [4] and surface roughness of the machined surface [5-7], become quicker. More and more papers deal with the examination of residual stresses [8] and changes on the texture [9] taking part on the surface. This is the reason why these features decisively determine the lifetime and reliability of the products [10]. The differently manufactured parts' accuracy is analysed, examined, and compared [11] because parts can be produced with higher accuracy by the newly developed cutting tools [12-14].

During operation, the maximum load of machine tools has effect on the surface of machine elements for a certain depth, so their quality has a great influence mainly on fatigue and so for the operational safety. Burnishing belongs to cold plastic manufacturing which has significant role in forming technology.

\footnotetext{
${ }^{*}$ Corresponding author: gyulavarga@,uni-miskolc.hu
} 
By its application the surface roughness, the micro-hardness and the corrosion resistance can be increased, just as shape correctness of cylindrical surfaces can be improved [15, 16]. In most cases diamond burnishing can be more effective than conventional chip removal finishing processes as grinding, lapping and polishing. Because of it the working process can be more time and cost effective. Furthermore, environment friendly processing can be implemented because it is chipless so it does not require high volume of coolants and lubricants [17].

The procedure of burnishing is performed for final finishing manufacturing of inner and outer cylindrical surfaces, the main areas of its applications are automotive and aeronautics industries. This study deals with the examination of outer cylindrical surfaces only.

The experiments were performed using the Factorial Experiment Design [18, 19]. Some paper as [20] presented the classification and short description of design of experiment (DoE) methods. The design of experiment is used to determine optimal process parameters in the manufacturing industry, such as for the end milling processes [21].

\section{Burnishing of outer cylindrical surfaces}

In diamond burnishing the reduction of surface roughness and improving of shape correctness of the surface is caused by the interaction between the tool - which material much harder than the workpiece - and the workpiece while performing rotational and linear movement with sliding friction between them (Fig. 1) [22].

The material of the working part of the burnishing tool can be hardened steel, carbide, mineral ceramics and natural or artificial diamond.

The pressure that is necessary for realizing of cold shaping arrives from the overlapping between the working part of the tool and the surface to be formed of the workpiece. Plastic deformation is realised in 0.01-0.2 mm thick layer in the subsurface of the workpiece because of the static content of the shaping element (burnishing tool) and the outer surface of the workpiece [23-24].

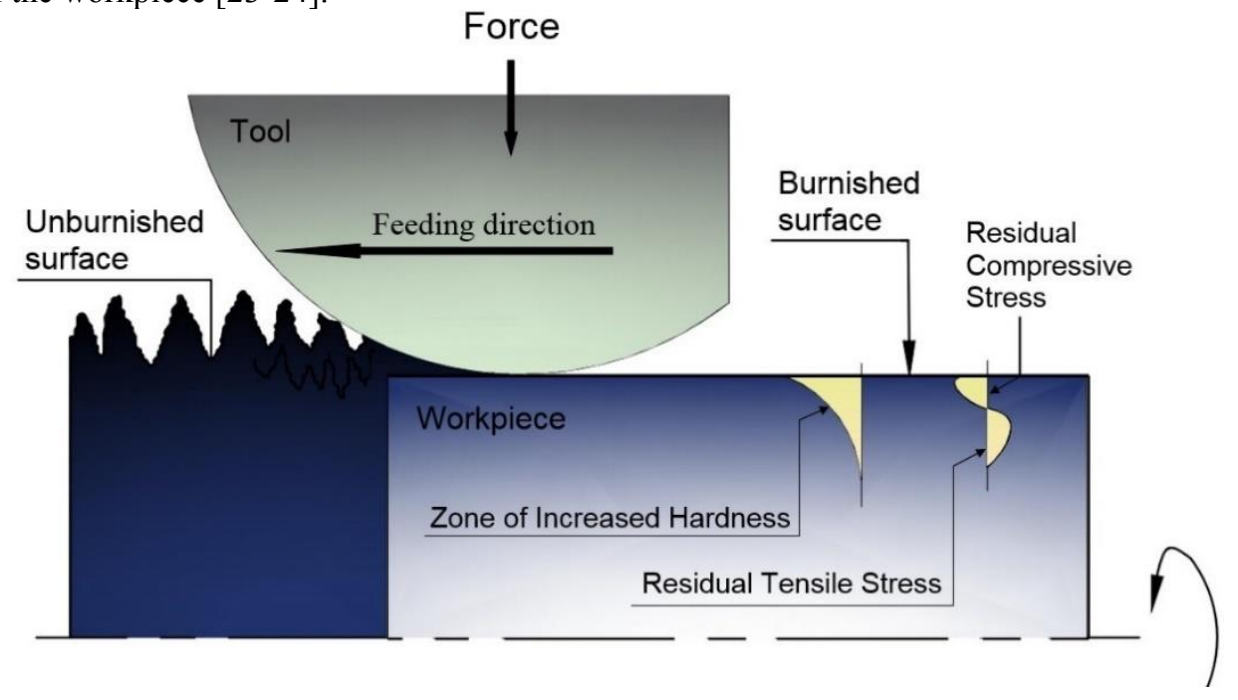

Fig. 1. Schematic illustration of burnishing process [22].

Burnishing of outer cylindrical surfaces can be executed on conventional universal lathes or up-to-date CNC lathes. 


\section{Experimental conditions}

During the experiments, a CNC lathe with flatbed produced by firm OPTIMUM type OPTIturn S600 was used. For the examination, we have chosen hardened steel mark C60 $(\mathrm{Rm}=730-1100 \mathrm{MPa}, 850-900 \mathrm{HV})$ as workpiece material and its chemical composition can be found in Table 1 [25]. It was turned to $49 \mathrm{~mm}$ diameter dislocated to 5 parts, each of them being $25 \mathrm{~mm}$ long (Fig. 2). PCD (polycrystalline diamond) tool was used with 3.5 $\mathrm{mm}$ radius and the applied oil kinematic viscosity was $70 \mathrm{~mm}^{2} / \mathrm{s}$.

Table 1. Chemical composition of the burnished specimens [25].

\begin{tabular}{|l|c|c|c|c|c|c|c|c|}
\hline Elements & $\mathrm{C}$ & $\mathrm{Si}$ & $\mathrm{Mn}$ & $\mathrm{P}$ & $\mathrm{S}$ & $\mathrm{Cr}$ & $\mathrm{Mo}$ & $\mathrm{Ni}$ \\
\hline Chemical composition & 0.57 & $\max$ & 0.60 & $\max$ & $\max$ & $\max$ & $\max$ & \multirow{2}{*}{0.40} \\
(Typical analysis in \%) & 0.65 & 0.40 & 0.90 & 0.045 & 0.045 & 0.4 & 0.1 & \\
\hline
\end{tabular}

Measurement of the cylindricity was done with a circular and position error measuring machine type Talyrond 365 [26]. In this investigation, inductive sensor was applied for measuring before and after burnishing in $3 \mathrm{~mm}$ distance.

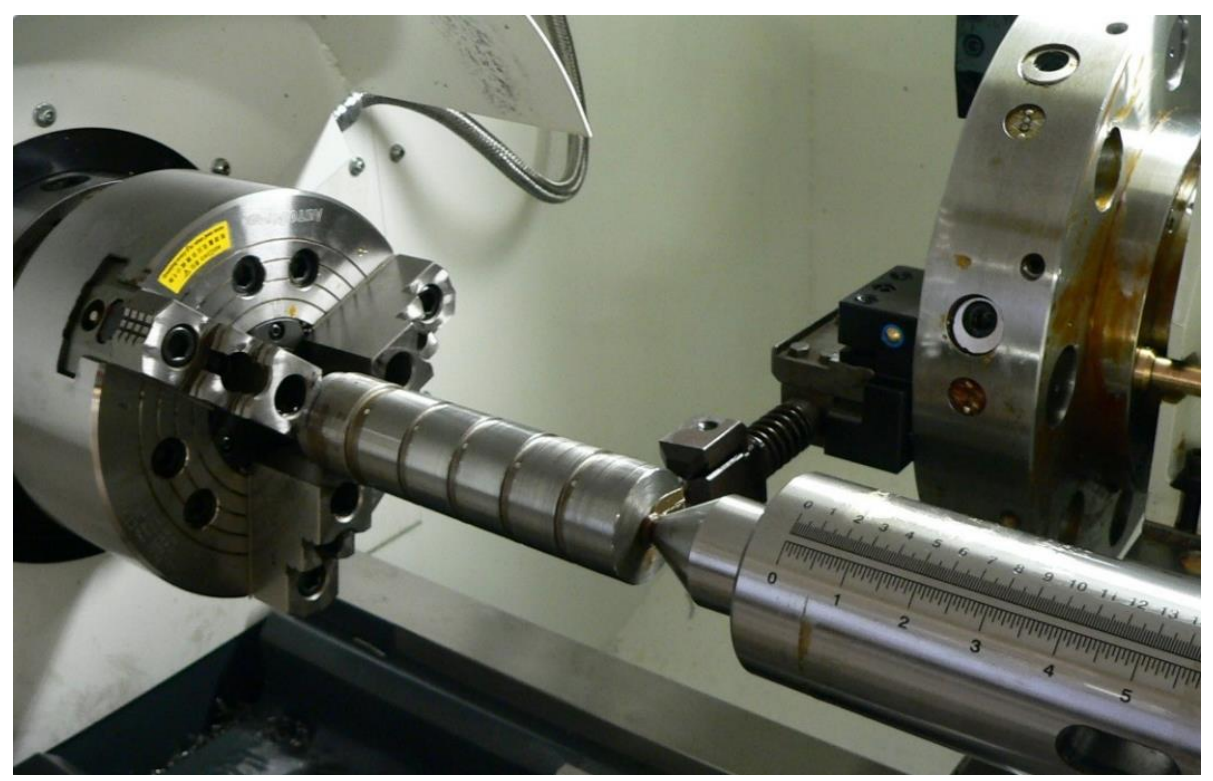

Fig. 2. Execution of diamond burnishing process [27].

In all 16 cylindricity indices were analysed and 4 of them were chosen and examined which mostly determine operating properties. These are: CYLp - peak to reference cylindricity deviation; CYLv - reference to valley cylindricity deviation; CYLt - peak to valley cylindricity deviation and CYLtt - cylinder taper [28], illustrates the rate of conicity as it can be seen in the Fig. 3 [29]. The above mentioned cylindricity parameters are included in standard ISO 12180-1.

Examined parameters: burnishing speed, feed rate and burnishing force which parameter ranges are following:

Feed rate: $\quad f_{1}=0.05 \mathrm{~mm} / \mathrm{rev}$ and $\mathrm{f}_{2}=0.10 \mathrm{~mm} / \mathrm{rev}$

Burnishing force: $\quad F_{b 1}=50 \mathrm{~N}$ and $F_{b 2}=100 \mathrm{~N}$ 
The matrix of the Taguchi type Factorial Experimental Design [18] can be seen on Table 2, which contains the burnishing parameters in natural dimensions and their transformed values.

\section{Centre of motion}

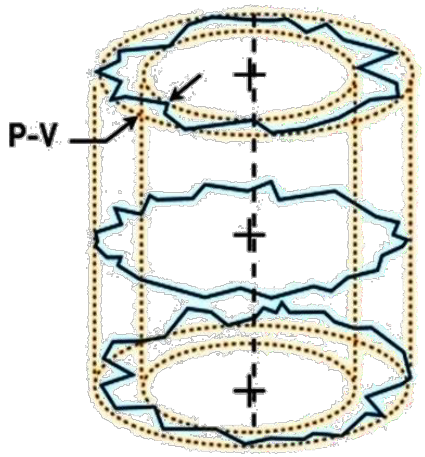

a)

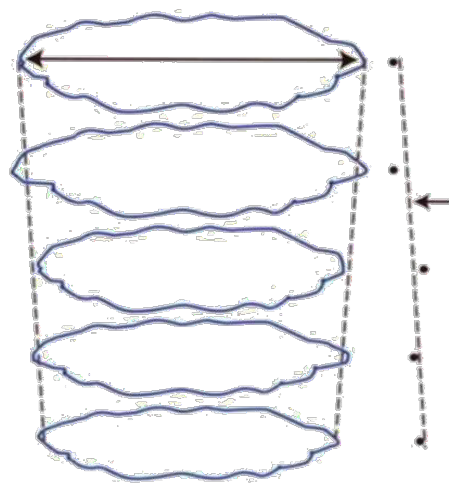

The shortest perpendicular

linear across the profile

side at the

intersection

b)

Fig. 3. Cylindricity parameters: CYLp, CYLv, CYLt (a) and CYLtt (b) [25].

Table 2. Applied burnishing parameters.

\begin{tabular}{|c|c|c|c|c|c|c|}
\hline \multirow{2}{*}{$\begin{array}{c}\text { Sign of } \\
\text { experiments }\end{array}$} & \multicolumn{3}{|c|}{ Burnishing parameters } & \multicolumn{3}{c|}{ Transformed parameters } \\
\cline { 2 - 7 } & $\mathrm{Vb}[\mathrm{m} / \mathrm{min}]$ & $\mathrm{f}[\mathrm{mm} / \mathrm{rev}]$ & $\mathrm{Fb}_{\mathrm{b}}[\mathrm{N}]$ & $\mathrm{X}_{1}$ & $\mathrm{X}_{2}$ & $\mathrm{X}_{3}$ \\
\hline 1 & 40 & 0.05 & 50 & -1 & -1 & -1 \\
\hline 2 & 80 & 0.05 & 50 & +1 & -1 & -1 \\
\hline 3 & 40 & 0.10 & 50 & -1 & +1 & -1 \\
\hline 4 & 80 & 0.10 & 50 & +1 & +1 & -1 \\
\hline 5 & 40 & 0.05 & 100 & -1 & -1 & +1 \\
\hline 6 & 80 & 0.05 & 100 & +1 & -1 & +1 \\
\hline 7 & 40 & 0.10 & 100 & -1 & +1 & +1 \\
\hline 8 & 80 & 0.10 & 100 & +1 & +1 & +1 \\
\hline
\end{tabular}

During examination, the improvement ratios of the different cylindricity parameters were created, the generalized formula of it can be seen in formula (1):

where:

$$
\rho_{C Y L X}=\frac{C Y L x_{b}-C Y L x_{g}}{C Y L x_{b}} \cdot 100 \quad, \%
$$

$\rho_{\text {CYLx }}$ Improvement ratio without dimension to be indicative the change of cylindricity parameter that caused by burnishing process

CYLx Different cylindricity parameters. $x$ (in this experimental) adds value of $p$, $v, t$, and $t t$, so it is equal to CYLp, CYLv, CYLt and CYLtt parameters

CYLx $_{g}$ Measured cylindricity parameters after grinding

$\mathrm{CYLx}_{\mathrm{b}}$ Measured cylindricity parameters after burnishing

The smallest are the different rates in the negative range, the greater is the improvement. 


\section{Results}

The values of the measurements can be seen in Table 3. with the percental values of the improvement ratios calculated from them.

Table 3. Measured values of the cylindricity parameters.

\begin{tabular}{|c|c|c|c|c|c|c|}
\hline \multirow{2}{*}{$\begin{array}{l}\text { Sign of } \\
\text { the } \\
\text { workp. }\end{array}$} & \multicolumn{2}{|c|}{ CYLp $[\mu \mathrm{m}]$} & \multirow{2}{*}{$\begin{array}{c}\rho_{C Y L p} \\
{[\%]}\end{array}$} & \multicolumn{2}{|c|}{ CYLv $[\mu \mathrm{m}]$} & \multirow{2}{*}{$\begin{array}{c}\rho_{C Y L v} \\
{[\%]}\end{array}$} \\
\hline & CYLp $_{\mathrm{g}}$ & CYLp $_{b}$ & & $\mathrm{CYLv}_{\mathrm{g}}$ & $\mathrm{CYLv}_{\mathrm{b}}$ & \\
\hline 1 & 11.33 & 15.58 & 27.27 & 2.71 & 4.07 & 33.41 \\
\hline 2 & 19.98 & 21.13 & 5.44 & 3.34 & 4.07 & 17.94 \\
\hline 3 & 21.93 & 18.15 & -20.82 & 2.53 & 3.42 & 26.03 \\
\hline 4 & 10.37 & 44.14 & 76.50 & 3.04 & 10.97 & 72.29 \\
\hline 5 & 14.56 & 15.75 & 7.56 & 2.97 & 4.04 & 26.49 \\
\hline 6 & 20.63 & 18.45 & -11.81 & 2.60 & 3.58 & 27.38 \\
\hline 7 & 21.16 & 18.49 & -14.44 & 2.57 & 3.59 & 28.42 \\
\hline 8 & 16.66 & 20.34 & 18.1 & 2.78 & 3.66 & 24.05 \\
\hline
\end{tabular}

\begin{tabular}{|c|c|c|c|c|c|c|}
\hline \multirow{2}{*}{$\begin{array}{c}\text { Sign of } \\
\text { the } \\
\text { workp. }\end{array}$} & \multicolumn{2}{|c|}{ CYLt $[\mu \mathrm{m}]$} & \multirow{2}{*}{\begin{tabular}{c}
$\rho_{\text {CYLt }}$ \\
\cline { 5 - 6 }
\end{tabular}} & CYLt $_{\mathrm{g}}$ & CYLtb & \multicolumn{2}{c|}{ CYLtt $[\mu \mathrm{m}]$} & \multirow{2}{*}{$\begin{array}{c}\rho_{\text {CYLtt }} \\
{[\%]}\end{array}$} \\
\hline 1 & 14.04 & 19.92 & 29.51 & -6.67 & 18.53 & 135.99 \\
\hline 2 & 23.33 & 25.20 & 7.43 & -20.96 & -20.48 & -2.34 \\
\hline 3 & 24.46 & 21.56 & -13.45 & -17.58 & -13.14 & -33.78 \\
\hline 4 & 13.40 & 55.12 & 76.69 & -4.35 & 48.84 & 108.90 \\
\hline 5 & 17.53 & 19.78 & 11.38 & -9.81 & -14.88 & -34.07 \\
\hline 6 & 23.23 & 22.02 & -5.49 & -9.97 & -8.67 & -14.99 \\
\hline 7 & 23.72 & 22.09 & -7.37 & -17.27 & -9.13 & -89.15 \\
\hline 8 & 19.44 & 24.00 & 19.00 & -12.19 & -16.37 & -25.53 \\
\hline
\end{tabular}

By the use of Factorial Experiment Design empirical formulas (2-5) can be determined. Calculations and demonstrations of the functions were done by using the MathCad software (Fig. 4-5).

$$
\begin{aligned}
\rho_{C Y L_{p}}= & 331.84-5.267 \cdot v_{b}-5.211 \cdot 10^{3} \cdot f-2.31 \cdot F_{b}+93.195 \cdot v_{b} \cdot f+ \\
& 0.035 \cdot v_{b} \cdot F_{b}+37.332 \cdot f \cdot F_{b}-0.672 \cdot v_{b} \cdot f \cdot F_{b} \\
\rho_{C Y L_{t}}= & 217.57-4.014 \cdot v_{b}-2.908 \cdot 10^{3} \cdot f-1.992 \cdot F_{b}+64.36 \cdot v_{b} \cdot f+ \\
& 0.042 \cdot v_{b} \cdot F_{b}+30.52 \cdot f \cdot F_{b}-0.67 \cdot v_{b} \cdot f \cdot F_{b} \\
\rho_{C Y L_{t}}= & 323.3-5.212 \cdot v_{b}-4.967 \cdot 10^{3} \cdot f-2.331 \cdot F_{b}+90.6 \cdot v_{b} \cdot f+ \\
& 0.037 \cdot v_{b} \cdot F_{b}+37.276 \cdot f \cdot F_{b}-0.69 \cdot v_{b} \cdot f \cdot F_{b} \\
\rho_{C Y L_{t t}=} & 1.4037 \cdot 10^{3}-20.331 \cdot v_{b}-1.604 \cdot 10^{4} \cdot f-13.573 \cdot F_{b}+ \\
& 258.74 \cdot v_{b} \cdot f+0.197 \cdot v_{b} \cdot F_{b}+140.464 \cdot f \cdot F_{b}-2.365 \cdot v_{b} \cdot f \cdot F_{b}
\end{aligned}
$$




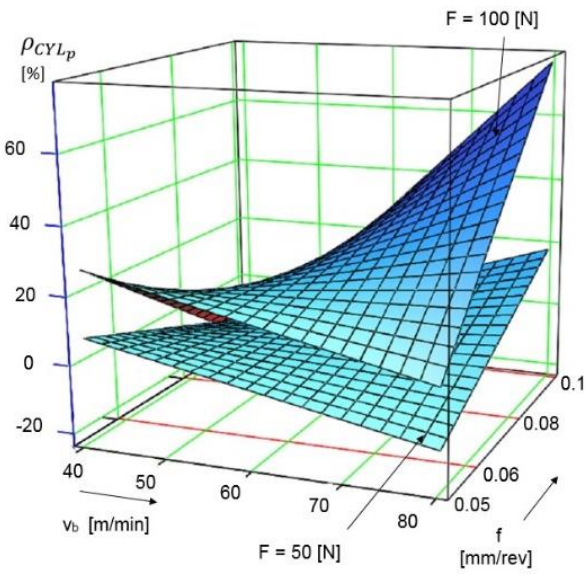

a)

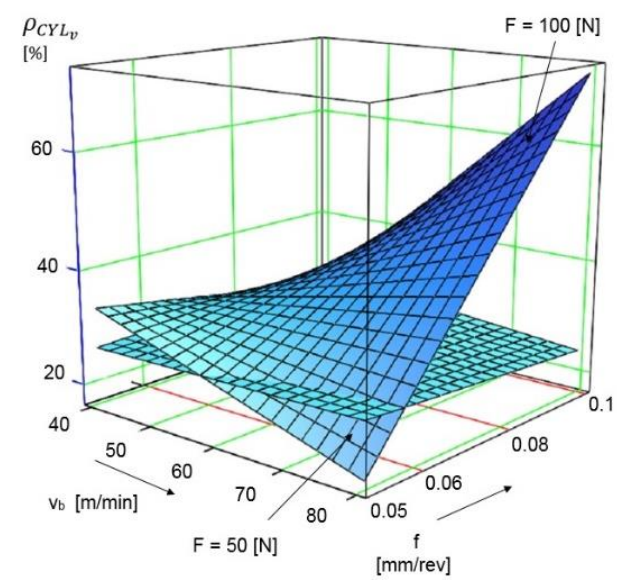

b)

Fig. 4. Experimental results in the point of view of peaks (a) and valleys (b) of the cylindricity error.

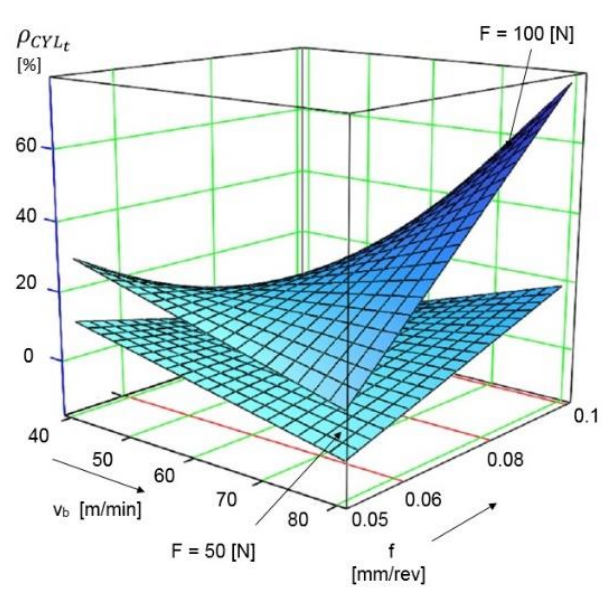

a)

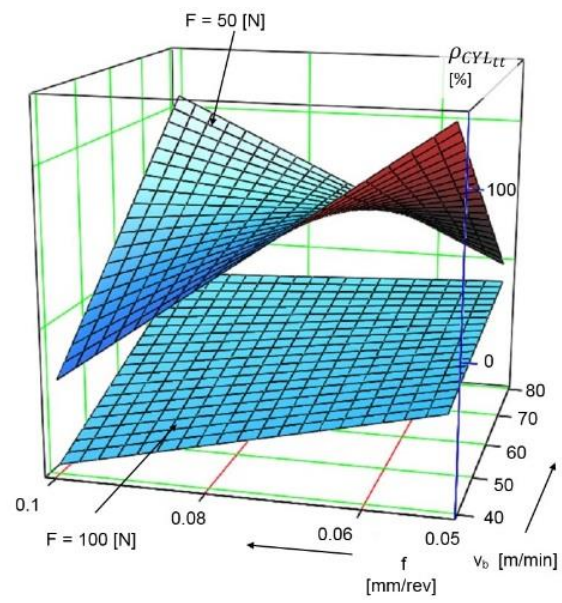

b)

Fig. 5. Experimental results in the point of view of largest deviations (a) and conicity of the cylindricity error (b).

Fig. 4-5 show the extent of the improvement of the executed sliding burnishing. It can be stated that the application lower burnishing speed $\left(\mathrm{v}_{\mathrm{b} 1}=40 \mathrm{~m} / \mathrm{min}\right)$ with higher feed rate $\left(f_{2}=0.1 \mathrm{~mm} / \mathrm{rev}\right)$ when the burnishing force is lower $\left(F_{b 1}=50 \mathrm{~N}\right)$ show the highest improvement of CYLp and CYLt. When the burnishing force is higher $\left(\mathrm{F}_{\mathrm{b} 2}=100 \mathrm{~N}\right)$ in that case the improvement is worse by $6.38 \%$ related to the CYLp and $7.07 \%$ related to CYLt. In case of CYLv the higher burnishing speed $\left(\mathrm{v}_{\mathrm{b} 2}=80 \mathrm{~m} / \mathrm{min}\right)$ with lower feed rate $\left(f_{1}=0.05 \mathrm{~mm} / \mathrm{rev}\right)$ when the burnishing force is lower $\left(\mathrm{F}_{\mathrm{b} 1}=50 \mathrm{~N}\right)$ showed the higher improvements. Increasing the burnishing force to the higher value $\left(\mathrm{F}_{\mathrm{b} 2}=100 \mathrm{~N}\right)$ without changing the value of the other two parameters the improvement ratio of CYLv is reducing by $9.44 \%$. From the conicity point of view when the feed rate $\left(f_{2}=0.1 \mathrm{~mm} / \mathrm{rev}\right)$ and burnishing force $\left(F_{b 2}=100 N\right)$ is higher and the burnishing speed is lower $\left(\mathrm{v}_{\mathrm{b} 1}=40 \mathrm{~m} / \mathrm{min}\right)$ show the best result. By increasing the burnishing speed to the higher value, the improvement value is reducing by $63.62 \%$. 


\section{Summary}

The paper dealt with the experimental analysis of sliding burnishing when the material of the workpiece was hardened steel. Experimental parameters were the burnishing speed, feed rate and burnishing force.

The aim of the experiments was to determine how these parameters have effect to the shape correctness. The experiments were executed and evaluated on the base of Taguchi type Full Factorial Experiment Design. The evaluation was more visible by the use of the dimensionless improvement ratios of different cylindricity parameters $\left(\rho_{C Y L_{p}}, \rho_{C Y L_{v}}, \rho_{C Y L_{t}}\right.$, $\left.\rho_{C Y L_{t t}}\right)$. After determining the empirical formulas their $3 \mathrm{D}$ demonstrations gave to the evaluation a graphical perspective.

On the base of the present research work it can be stated:

- The results of $\rho_{C Y L_{t}}$ (improvement ratio of peak to valley cylindricity deviation) which was calculated from the most frequently used cylindricity parameter (CYLt) are very much similar to the results of $\rho_{C Y L_{p}}$ (improvement ratio of peak to reference cylindricity deviation). According to it the total shape correctness was consisted of peaks (CYLp) in the examined parameter ranges.

- The higher improvement was caused, from the peaks and valleys point of view, by the application of these burnishing parameters:

$$
\mathrm{v}_{\mathrm{b} 1}=40 \mathrm{~m} / \mathrm{min} ; \mathrm{f}_{2}=0.1 \mathrm{~mm} / \mathrm{rev} ; \mathrm{F}_{\mathrm{b} 1}=50 \mathrm{~N} \text {. }
$$

- From the point of view of conicity the improvement was served by setting the burnishing parameters to:

$$
\mathrm{v}_{\mathrm{b} 1}=40 \mathrm{~m} / \mathrm{min} ; \mathrm{f}_{2}=0.1 \mathrm{~mm} / \mathrm{rev} ; \mathrm{F}_{\mathrm{b} 2}=100 \mathrm{~N} \text {. }
$$

"Project no. NKFI-125117 has been implemented with the support provided from the National Research, Development and Innovation Fund of Hungary, financed under the K_17 funding scheme.” "The described study was carried out as part of the EFOP-3.6.1-16-00011 "Younger and Renewing University - Innovative Knowledge City - institutional development of the University of Miskolc aiming at intelligent specialisation" project implemented in the framework of the Szechenyi 2020 program. The realization of this project is supported by the European Union, co-financed by the European Social Fund."

\section{References}

1. P. Tamás, B. Illés, Acad. J. of Manuf. Eng. 14 4, 119 (2016)

2. P. Tamás, B. Illés, P. Dobos, IOP Conf. Series: Mat. Sci. and Eng. 161, 1 (2016)

3. M. Rusko, R. Kralikova, Advanced Mat. Research 816-817, 1225 (2013)

4. M.H. El-Axir, O.M. Othman, A.M. Abodiena, J. Mat. Proc. Tech. 196 1-3, 120 (2008)

5. J. Kundrák, K. Gyáni, V. Bana, Int. J. of Adv. Manuf. Techn. 38 1-2, 110 (2008)

6. C. Felhő, J. Kundrák, Key Eng. Materials 496 pp.: 194-199 (2012)

7. G. Varga, Key Eng. Mat. 581 pp.: 403-408 (2014)

8. M. Novák, Manuf. Technology 12 pp.: 66-70 (2012)

9. J. Kundrák, Z. Gácsi, K. Gyáni, V. Bana, G. Tomolya, Int. J. of Adv. Manuf. Techn., 62 5-8, 457 (2012)

10. W. Zebala, B. Slodki, G. Struzikiewicz, Case Study. Eksploatacja i Niezawodnosc Maint. and Reliability 15 4, 421 (2013)

11. J. Kundrák, A.G. Mamalis, A. Markopoulos, Materials and Manuf. Proc. 19 6, 979 (2004)

12. G. Dezső, J. Herman, F. Szigeti, Int. J. of Eng. X 1, 155 (2012) 
13. I. Sztankovics, J Kundrák, Manuf. Techn. 141 pp.: 97-104 (2014)

14. J. Beňo, I. Maňková, M. Vrabel', D. Kottfer, Measurement 461 pp.: 582-592 (2013)

15. M.R. Stalin John, P. Suresh, D. Raguraman, B.K. Vinayagam, Arab J. SciEng. 39 pp.: 3209-3216 (2014)

16. A. Akkurt, Metal Sci. and Heat Treatm. 53 3-4 pp.: 145-150 (2011)

17. M. Polankova, F. Manlig, R. Králiková, MM Science Journal. pp.: 691-695, (2015)

18. G. Taguchi, System of experiment design, 1. Experimental design (UNIPUB, Kraus International Publications, White Plains, New York, 1987)

19. L. Fridrik, Chosen chapters from the topics of experimental design of production engineering (Müszaki Könyvkiadó, Budapest, 1987) (In Hungarian)

20. Á. Drégelyi-Kiss, R. Horváth, B. Mikó, Dev. in Mach. Technol. 3. Ed.: W. Zebala, I. Manková, Cracow University of Technology pp.: 20-34 (2013)

21. M.N. Durakbasa, A. Akdogan, S. Vanli, A. Gunay Bulutsuz, Measurement 68 pp.: $92-$ 99 (2015)

22. A. Akkurt, J. of Materials Eng. and Perform. 206 pp.: 960-968, (2011)

23. L. Luca, S. Neagu-Ventzel, I. Marinescu, Prec. Eng. (Elsevier) 29 pp.: 253-256 (2005)

24. T.A. El-Taweel, M.H. El-Axir, The Int. J. of Adv. Manuf. Techn. 41 pp. 301-310, (2009)

25. G. Varga, Key Eng. Mat. 581 pp.: 403-408 (2014)

26. http://www.steelnumber.com/en/steel_composition_eu.php?name_id=154 (09.01.2017)

27. V. Ferencsik, Sci. Students' Conf., University of Miskolc, pp.: 1-34 (2013) (In Hungarian)

28. D.J. Whitehouse, Handbook of Surface and Nanometrology, Second edition, (CRC Press, Taylor and Francis Group, 2011)

29. N.N., Study aid, Taylor Hobson Precision, p.: 34 (In Hungarian) (2013) 